\title{
Ketamine suppresses the substance $P$-induced production of IL-6 and IL-8 by human U373MG glioblastoma/astrocytoma cells
}

\author{
KEISUKE YAMAGUCHI $^{1}$, SEIICHIRO KUMAKURA ${ }^{1}$, TAISUKE MURAKAMI ${ }^{2}$, \\ AKIMASA SOMEYA $^{2}$, EIICHI INADA ${ }^{1}$ and ISAO NAGAOKA ${ }^{2}$ \\ Departments of ${ }^{1}$ Anesthesiology and Pain Medicine, and ${ }^{2}$ Host Defense and Biochemical Research, \\ Juntendo University Graduate School of Medicine, Tokyo 113-8421, Japan
}

Received October 20, 2015; Accepted January 19, 2017

DOI: $10.3892 / \mathrm{ijmm} .2017 .2875$

\begin{abstract}
The neuropeptide substance P (SP) is an important mediator of neurogenic inflammation within the central and peripheral nervous systems. SP has been shown to induce the expression of pro-inflammatory cytokines implicated in the pathogenesis of several disorders of the human brain via the neurokinin-1 receptor (NK-1R). Ketamine, an intravenous anesthetic agent, functions as a competitive antagonist of the excitatory neurotransmission $N$-methyl-D-aspartate (NMDA) receptor, and also antagonizes the NK-1R by interfering with the binding of SP. In the present study, we investigated the anti-inflammatory effects of ketamine on the SP-induced activation of a human astrocytoma cell line, U373MG, which expresses high levels of NK-1R. The results from our experiments indicated that ketamine suppressed the production of interleukin (IL)- 6 and IL-8 by the U373MG cells. Furthermore, ketamine inhibited the SP-induced activation of extracellular signal-regulated kinase (ERK)1/2, p38 mitogen-activated protein kinase (MAPK) and nuclear factor- $\kappa \mathrm{B}(\mathrm{NF}-\kappa \mathrm{B})$. Taken together, these observations suggest that ketamine may suppress the SP-induced activation (IL-6 and IL-8 production) of U373MG cells by inhibiting the phosphorylation of signaling molecules (namely ERK1/2, p38 MAPK and NF-кB), thereby exerting anti-inflammatory effects. Thus, ketamine may modulate SP-induced inflammatory responses by NK-1R-expressing cells through the suppression of signaling molecules (such as ERK1/2, p38 MAPK and NF- $\kappa$ B).
\end{abstract}

Correspondence to: Professor Isao Nagaoka, Department of Host Defense and Biochemical Research, Juntendo University Graduate School of Medicine, 2-1-1 Hongo, Bunkyo-ku, Tokyo 113-8421, Japan

E-mail: nagaokai@juntendo.ac.jp

Key words: ketamine, substance $\mathrm{P}$, extracellular signal-regulated kinase $1 / 2$, p38 mitogen-activated protein kinase, nuclear factor- $\kappa B$, neurokinin-1 receptor, $N$-methyl-D-aspartate receptor, interleukin-6, interleukin-8, U373MG cell, anti-inflammatory effect

\section{Introduction}

The neuropeptide substance P (SP) is an important mediator of neurogenic inflammation within the central and peripheral nervous systems. SP has been implicated in pain, and also plays important roles in cancer (e.g., tumor cell proliferation, anti-apoptotic effects on tumor cells, angiogenesis, tumor cell invasion and metastasis) (1-8). SP is released from primary afferent nociceptors and sympathetic post-ganglionic neurons, and activates neighboring receptors, thereby triggering and spreading activation (6-11). Moreover, SP has been shown to induce the expression of pro-inflammatory cytokines, such as interleukin (IL)-6 and IL-8 $(12,13)$, which are involved in the pathogenesis of several disorders of the human brain (such as multiple sclerosis, dementia complex, and Alzheimer's disease) (14), although it is currently a matter of debate as to whether SP plays a pathogenic or a protective role in these disorders. Previous research has indicated that the activation of an SP receptor [neurokinin-1 receptor (NK-1R)] elicits signals affecting the gene expression of some inflammatory cytokines (13). In addition, it has been reported that nanomolar concentrations of SP potently trigger the activation of nuclear factor- $\kappa \mathrm{B}(\mathrm{NF}-\kappa \mathrm{B})$, an important transcriptional activator, which regulates the production of various cytokines and other proinflammatory mediators (13).

The mitogen-activated protein kinase (MAPK) family of protein Ser/Thr kinases consists of at least three major subfamilies: i) the p42/44 MAPKs, which are also known as the extracellular signal-regulated kinases (ERKs)1/2; ii) the c-Jun $\mathrm{NH}_{2}$-terminal kinase/stress-activated protein kinases (JNK/SAPKs), including p46 JNK-1 and p54 JNK2; and iii) the p38 MAPK subfamily. MAPKs are activated under conditions of stress in response to a number of extracellular stimuli, including oxidative stress. Among these, the phosphorylation of p38 MAPK is induced in the dorsal horn of the spinal cord and in the dorsal root ganglia following peripheral nerve injury or inflammation (15-17), and the phosphorylation of ERK $1 / 2$ is induced by inflammatory stimuli in the trigeminal nucleus and the dorsal horn $(16,18,19)$.

The release of glutamate and SP from the primary afferents, activates $N$-methyl-D-asparate (NMDA) receptors 
and NK-1Rs, respectively, thereby resulting in the increase of intracellular calcium concentrations in the dorsal horn neurons, the activation of phospholipase $\mathrm{A}_{2}\left(\mathrm{PLA}_{2}\right)(20,21)$ and the production of prostaglandins by constitutively expressed spinal cyclooxygenase-2 (COX-2) (22). Ketamine, an intravenous anesthetic agent, functions as a competitive antagonist of the excitatory neurotransmission NMDA receptor (23) and also antagonizes the NK-1R by interfering with the binding of SP (24). Notably, the anti-inflammatory effect of ketamine has also been demonstrated in various animal models, where it was observed that ketamine markedly suppressed the production of tumor necrosis factor- $\alpha$ (TNF- $\alpha$ ) and IL- 6 following the stimulation of macrophages and peripheral leucocytes by lipopolysaccharide (LPS) (25). Moreover, it has been reported that ketamine inhibits the systemic production of inflammatory molecules by inhibiting the NF- $\kappa \mathrm{B}$ signaling pathway (26). Based on these findings, we hypothesized that ketamine may also act on NK-1R (SP) and exert anti-inflammatory effects by modulating the MAPK and $\mathrm{NF}-\kappa \mathrm{B}$ signaling pathways.

Thus, in the present study, we examined the anti-inflammatory effects of ketamine on the SP-induced activation of the human astrocytoma cell line, U373MG, which expresses high levels of NK-1R.

\section{Materials and methods}

Materials. The U373MG cell line (Uppsala; ECACC 08061901) was purchased from the European Collection of Authenticated Cell Cultures (ECACC; Salisbury, UK). SP was obtained from Sigma-Aldrich (St. Louis, MO, USA); ketamine was purchased from Daiichi Sankyo Co., Ltd. (Tokyo, Japan); minimum essential medium (MEM), non-essential amino acids (NEAAs), sodium pyruvate and fetal bovine serum (FBS) were puchased from Gibco BRL Life Technologies (Grand Island, NY, USA). RIPA buffer with protease inhibitor cocktail, sample buffer solution with reducing reagent (6X) for SDS-PAGE, running buffer solution (10X) for SDS-PAGE, Blocking One and Protein Ladder One Multi-color (Broad Range) for SDS-PAGE were obtained from Nacalai Tesque, Inc. (Kyoto, Japan). A BCA protein assay reagent kit and enhanced chemiluminescence reagent, SuperSignal West Dura were purchased from Thermo Fisher Scientific (Rockford, IL, USA). Mini-PROTEAN ${ }^{\circledR}$ TGX $^{\mathrm{TM}}$ precast gel and TransBlot $^{\circledR}$ Turbo $^{\text {TM }}$ Mini PVDF transfer packs were purchased from Bio-Rad Laboratories, Inc. (Hercules, CA, USA), and a Cytometric Bead Array (Human Inflammatory Cytokine kit) was obtained from BD Biosciences (San Jose, CA, USA).

Antibodies. Anti-phospho-ERK1/2 MAPK (Thr202/Tyr204) rabbit antibody (\#9101), anti-ERK1/2 MAPK rabbit antibody (\#9102), anti-phospho-NF-кB p65 (Ser536) rabbit monoclonal antibody (mAb; \#3033), and anti-NF- $\kappa$ B p65 rabbit mAb (\#8242) were purchased from Cell Signaling Technology, Inc. (Danvers, MA, USA); anti-phospho p38 MAPK rabbit antibody (Thr180/Tyr182; V121A) was obtained from Promega Corp. (Madison, WI, USA); anti-p38 MAPK (p38/SAPK2 $\alpha$; 612168) mouse mAb was purchased from BD Biosciences. Horseradish peroxidase (HRP)-conjugated goat anti-rabbit IgG (AP132P) and
HRP-conjugated goat anti-mouse IgG/IgM (AP308P) were obtained from Chemicon International (Temecula, CA, USA).

Cell culture. The U373MG cells were cultured in MEM supplemented with $1 \%(\mathrm{v} / \mathrm{v})$ penicillin/streptomycin, NEAA, $1 \mathrm{mM}$ sodium pyruvate and $10 \%$ heat-inactivated FBS. The cells were maintained at $37^{\circ} \mathrm{C}$ in a $5 \% \mathrm{CO}_{2}$ humidified atmosphere.

Western blot analysis. The U373MG cells were plated into 12 -well tissue culture plates at a density of $2 \times 10^{5}$ cells/well and incubated in MEM supplemented with $10 \%$ FBS for $12 \mathrm{~h}$, followed by incubation in MEM supplemented with $0.5 \%$ FBS for $12 \mathrm{~h}$ at $37^{\circ} \mathrm{C}$. Subsequently, the cells were incubated with ketamine $(0.1$ and $1 \mathrm{mM}$ ) for $60 \mathrm{~min}$, and then stimulated with SP (100 nM) for $10 \mathrm{~min}$. Thereafter, the cells were washed 3 times with ice-cold phosphate-buffered saline (PBS) and lysed in $0.1 \mathrm{ml}$ of RIPA buffer $(50 \mathrm{mmol} / 1$ Tris- $\mathrm{HCl} \mathrm{pH} 7.6$, $150 \mathrm{mmol} / 1 \mathrm{NaCl}, 1 \%$ Nonidet P40, 0.5\% sodium deoxycholate, protease inhibitor cocktail and $0.1 \%$ SDS). The protein concentrations of cell lysates were measured using the Bradford assay (Thermo Fisher Scientific). The lysates were mixed with SDS-PAGE sample buffer $(62.5 \mathrm{mM}$ Tris- $\mathrm{HCl}$, pH 6.8, 2\% SDS, $10 \%$ glycerol, $0.05 \%$ bromphenol blue, and 5\% 2-mercaptoethanol), and applied to SDS-PAGE $10 \%$ gels (Mini-PROTEAN TGX precast gel; $15 \mu \mathrm{g}$ protein/lane). Thereafter, the separated proteins were electroblotted onto polyvinylidine fluoride membranes (Trans-Blot Turbo Mini PVDF Transfer packs). Following incubation with Blocking One (Nacalai Tesque, Inc.), the blots were probed with a 1,000-fold dilution of rabbit anti-phospho ERK1/2, antiphospho NF- $\kappa$ B or anti-phospho p38 MAPK antibody, and further probed with a 2,000-fold dilution of HRP-conjugated goat anti-rabbit IgG/IgM. The signals were detected by SuperSignal West Pico/Dura Chemiluminescent substrate (Thermo Fisher Scientific), and quantified using an LAS-3000 luminescent image analyzer and MultiGauge software (both from Fujifilm, Tokyo, Japan). Thereafter, the antibody was stripped using WB Stripping Solution Strong (Naclai Tesque, Inc.) at room temperature for $15 \mathrm{~min}$. The blots were probed with a 1,000-fold dilution of rabbit anti-ERK1/2, anti-NF- $\kappa$ B or anti-p38 MAPK antibody, and further probed with a 2,000-fold dilution of HRP-conjugated goat anti-rabbit IgG/IgM or HRP-conjugated goat anti-mouse IgG/IgM.

Quantification of IL-6 and IL-8 levels. The U373MG cells were plated into 12-well tissue culture plates at a density of $2 \times 10^{5}$ cells/well and incubated in MEM supplemented with $10 \%$ FBS for $12 \mathrm{~h}$, which was followed by incubation in MEM supplemented with $0.5 \% \mathrm{FBS}$ for $12 \mathrm{~h}$ at $37^{\circ} \mathrm{C}$. The cells were then incubated with ketamine $(1 \mathrm{mM})$ for $60 \mathrm{~min}$, and stimulated with SP (100 nM) for $24 \mathrm{~h}$. The culture supernatants were recovered, centrifuged at $12,000 \mathrm{x} \mathrm{g}$ for $10 \mathrm{~min}$, and the levels of IL- 6 and IL- 8 in the medium were measured using a Cytometric Bead Array Human Inflammatory Cytokine kit (BD Biosciences), according to the manufacturer's instructions.

Statistical analysis. Data are expressed as the means $\pm \mathrm{SD}$, and analyzed for significant differences using a one-way ANOVA followed by a multiple comparison test using GraphPad Prism version 6.0 for Windows (GraphPad Software, San Diego, CA, 


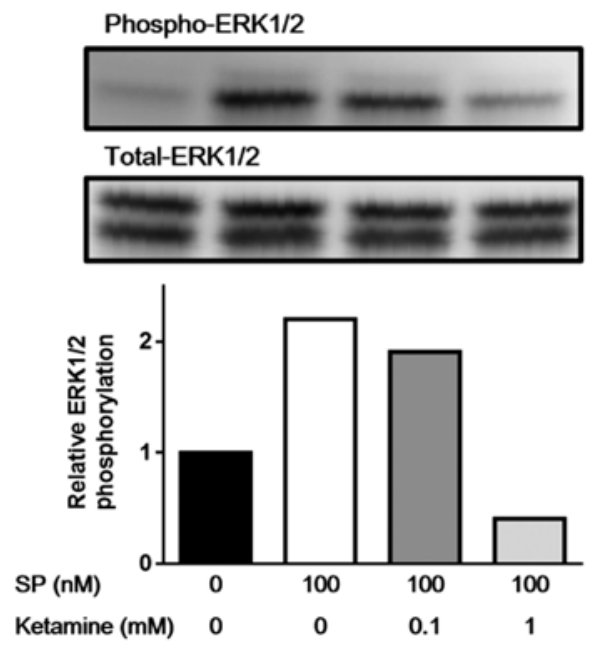

Figure 1. Dose-dependent inhibition of substance P (SP)-induced phosphorylation of extracellular signal-regulated kinase (ERK)1/2 by ketamine. The U373MG astrocytoma cells were plated into 12-well tissue culture plates at a density of $2 \times 10^{5}$ cells/well and incubated in MEM supplemented with $10 \%$ FBS for $12 \mathrm{~h}$, followed by incubation in MEM supplemented with $0.5 \%$ FBS for $12 \mathrm{~h}$ at $37^{\circ} \mathrm{C}$. Subsequently, the cells were incubated with or without ketamine $(0.1 \mathrm{mM}$ and $1 \mathrm{mM})$ for $60 \mathrm{~min}$, and then incubated with or without SP $(100 \mathrm{nM})$ for $10 \mathrm{~min}$. The phosphorylation of ERK1/2 was detected by probing with anti-phospho-ERK1/2 MAPK (Thr202/Tyr204) antibody and HRP-conjugated goat anti-rabbit IgG. In order to confirm that equal amounts of the proteins were analyzed in each sample, the blots were stripped, and total ERK1/2 were detected by reprobing with anti-ERK1/2 MAPK antibody and HRP-conjugated goat anti-rabbit IgG. A representative image is shown, and the data are expressed relative to the cells incubated without SP and ketamine.

USA). A P-value $<0.05$ was considered to indicate a statistically significant difference.

\section{Results}

Suppression of SP-induced ERK1/2 activation by ketamine. Firstly, we examined the dose-dependent effect of ketamine on the phosphorylation of ERK1/2. As shown in Fig. 1, SP stimulation $(100 \mathrm{nM})$ markedly induced the phosphorylation of ERK1/2 in the U373MG cells, and ketamine suppressed the SP-induced phosphorylation of ERK1/2 in a dose-dependent manner; the phosphorylation of ERK1/2 was only minimally inhibited by $0.1 \mathrm{mM}$ ketamine, whereas the concentration of $1 \mathrm{mM}$ ketamine caused marked inhibition. Thus, the concentration of $1 \mathrm{mM}$ ketamine was used to repeatedly evaluate the effect of ketamine on the SP-induced phosphorylation of ERK1/2. As shown in Fig. 2, $1 \mathrm{mM}$ ketamine significantly suppressed the SP-induced phosphorylation of ERK1/2 in the U373MG cells $(\mathrm{P}<0.05)$.

Suppression of the SP-induced activation of $p 38$ MAPK and $N F-\kappa B$ by ketamine. We then evaluated the effects of ketamine on the phosphorylation of $\mathrm{p} 38$ MAPK and NF- $\mathrm{KB}$. As shown in Fig. 3, stimulation of the U373MG cells with SP $(100 \mathrm{nM})$ markedly induced the phosphorylation of p38 MAPK, and ketamine $(1 \mathrm{mM})$ significantly suppressed the SP-induced phosphorylation of p38 MAPK $(\mathrm{P}<0.05)$. Similarly, stimulation of the U373MG cells with SP $(100 \mathrm{nM})$ markedly induced the phosphorylation of NF- $\mathrm{kB}$, and ketamine $(1 \mathrm{mM})$ significantly suppressed the SP-induced phosphorylation of NF-kB (Fig. 4; $\mathrm{P}<0.05$ ).
Phospho-ERK1/2

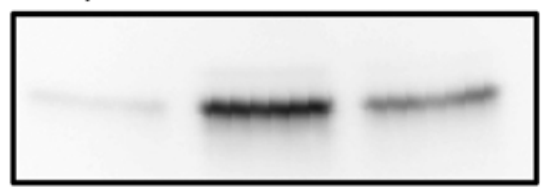

Total-ERK1/2
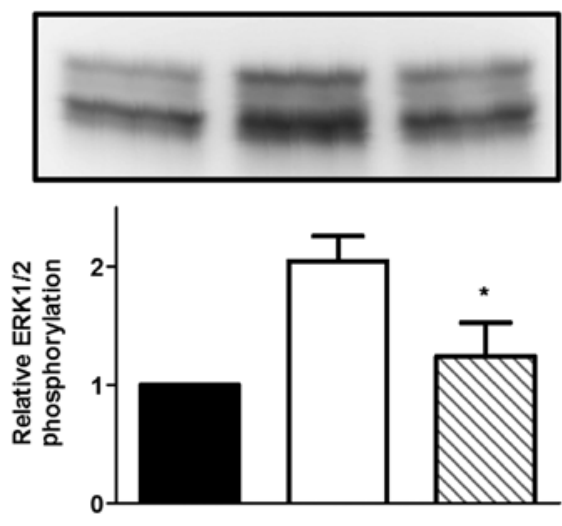

$\mathrm{SP}(100 \mathrm{nM})$

Ketamine (1 mM)

Figure 2. Inhibitory effect of ketamine on the substance P (SP)-induced phosphorylation of extracellular signal-regulated kinase (ERK)1/2. The U373MG cells were plated into 12-well tissue culture plates at a density of $2 \times 10^{5}$ cells/well and incubated in MEM supplemented with $10 \%$ FBS for $12 \mathrm{~h}$, followed by incubation in MEM supplemented with $0.5 \% \mathrm{FBS}$ for $12 \mathrm{~h}$ at $37^{\circ} \mathrm{C}$. Subsequently, the cells were incubated with or without ketamine $(1 \mathrm{mM})$ for $60 \mathrm{~min}$, and then incubated with or without SP $(100 \mathrm{nM})$ for $10 \mathrm{~min}$. The phosphorylation of ERK1/2 was detected by probing with anti-phospho-ERK1/2 MAPK (Thr202/Tyr204) antibody and HRP-conjugated goat anti-rabbit IgG. In order to confirm that equal amounts of the proteins were analyzed in each sample, the blots were stripped, and total ERK $1 / 2$ were detected by reprobing with anti-ERK1/2 MAPK antibody and HRP-conjugated goat anti-rabbit $\mathrm{IgG}$. A representative image is shown. Data are the means $\pm \mathrm{SD}$ of 3 separate experiments, and expressed relative to the cells incubated without SP and ketamine. Data are compared between the SP-stimulated cells incubated with and without ketamine, ${ }^{*} \mathrm{P}<0.05$.

Effects of ketamine on the SP-induced production of IL-6 and Il-8 by U373MG cells. Finally, we evaluated the effects of ketamine on the production of IL- 6 and IL- 8 by U373MG cells. As shown in Fig. 5, the levels of IL-6 and IL-8 in the cell culture supernatants were markedly increased following stimulation with SP $(100 \mathrm{nM})$. Notably, ketamine $(1 \mathrm{mM})$ significantly suppressed the production of both IL-6 and IL-8 $(\mathrm{P}<0.05)$.

\section{Discussion}

To the best of our knowledge, this is the first study to demonstrate the effects of ketamine on SP-induced inflammatory responses in U373MG glioblastoma/astrocytoma cells. In the present study, we revealed that ketamine suppressed the production of IL-6 and IL-8 in U373MG cells. Furthermore, ketamine inhibited the SP-induced activation of ERK1/2,p38 MAPK and NF- $\mathrm{KB}$. Thus, ketamine may suppress the SP-induced activation (IL-6 and IL-8 production) of U373MG cells by inhibiting the phosphorylation of signaling molecules (namely ERK1/2, p38 MAPK and NF- $\mathrm{KB}$ ), thereby exerting anti-inflammatory effects.

U373MG astrocytoma cells express a functional high-affinity SP receptor, NK-1R (27) and are capable of producing IL-6 in response to stimulation with SP (12). Thus, 


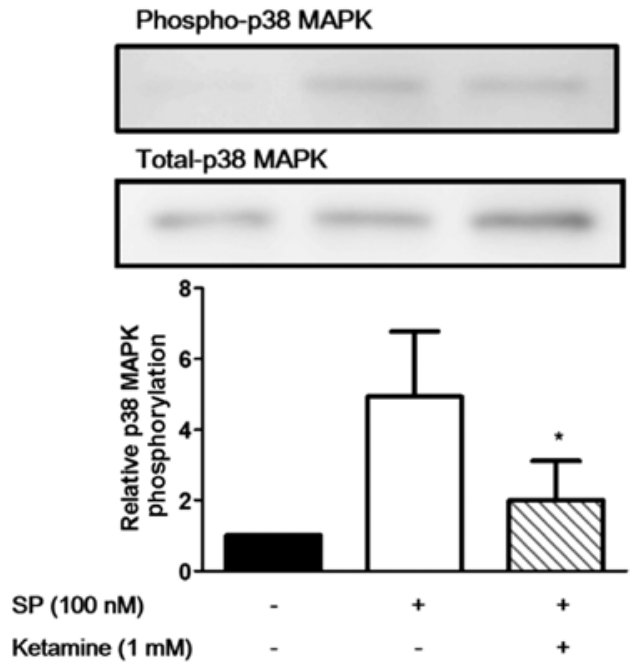

Figure 3. Inhibitory effect of ketamine on substance $\mathrm{P}(\mathrm{SP})$-induced phosphorylation of p38 mitogen-activated protein kinase (MAPK). The U373MG cells were plated into 12 -well tissue culture plates at a density of $2 \times 10^{5}$ cells/well and incubated in MEM with 10\% FBS for $12 \mathrm{~h}$, followed by incubation in MEM supplemented with $0.5 \%$ FBS for $12 \mathrm{~h}$ at $37^{\circ} \mathrm{C}$. Subsequently, the cells were incubated with or without ketamine $(1 \mathrm{mM})$ for $60 \mathrm{~min}$, and then incubated with or without SP $(100 \mathrm{nM})$ for $10 \mathrm{~min}$. The phosphorylation of p38 MAPK was detected by probing with anti-phospho p38 MAPK antibody and HRP-conjugated goat anti-rabbit IgG. In order to confirm that equal amounts of the proteins were analyzed in each sample, the blots were stripped, and total p38 MAPK were detected by reprobing with anti-p38 MAPK antibody and HRP-conjugated goat anti-mouse IgG. A representative image is shown. Data are the means $\pm \mathrm{SD}$ of 3 separate experiments, and expressed relative to the cells incubated without SP and ketamine. Data are compared between the SP-stimulated cells incubated with and without ketamine. ${ }^{*} \mathrm{P}<0.05$.

Phospho-NF-kB

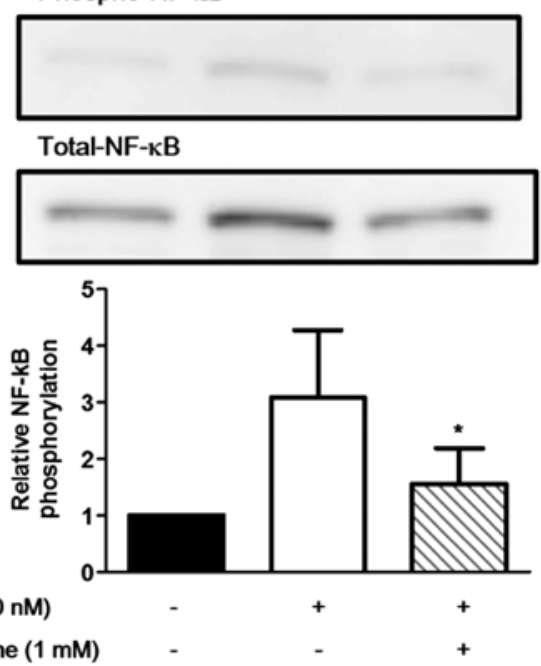

Figure 4. Inhibitory effect of ketamine on substance $\mathrm{P}(\mathrm{SP})$-induced phosphorylation of nuclear factor- $\mathrm{\kappa B}(\mathrm{NF}-\kappa \mathrm{B})$. The U373MG cells were plated into 12-well tissue culture plates at a density of $2 \times 10^{5}$ cells/well and incubated in MEM suplemented with $10 \%$ FBS for $12 \mathrm{~h}$, followed by incubation in MEM supplemented with $0.5 \% \mathrm{FBS}$ for $12 \mathrm{~h}$ at $37^{\circ} \mathrm{C}$. Subsequently, the cells were incubated with or without ketamine $(1 \mathrm{mM})$ for $60 \mathrm{~min}$, and then incubated with or without SP $(100 \mathrm{nM})$ for $10 \mathrm{~min}$. The phosphorylation of NF-кB was detected by probing with anti-phospho NF-kB p65 (Ser536) rabbit $\mathrm{mAb}$ and HRP-conjugated goat anti-rabbit IgG. In order to confirm that equal amounts of the proteins were analyzed in each sample, the blots were stripped, and total $\mathrm{NF}-\kappa \mathrm{B}$ were detected by reprobing with anti NF- $\mathrm{KB}$ p 65 rabbit $\mathrm{mAb}$ and HRPconjugated goat anti-rabbit IgG. A representative image is shown. Data are the means \pm SD of 3 separate experiments, and expressed relative to the cells incubated without SP and ketamine. Data are compared between the SP-stimulated cells incubated with and without ketamine. ${ }^{*} \mathrm{P}<0.05$
A

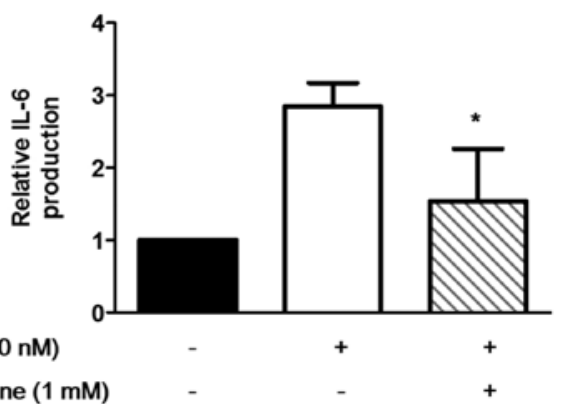

B

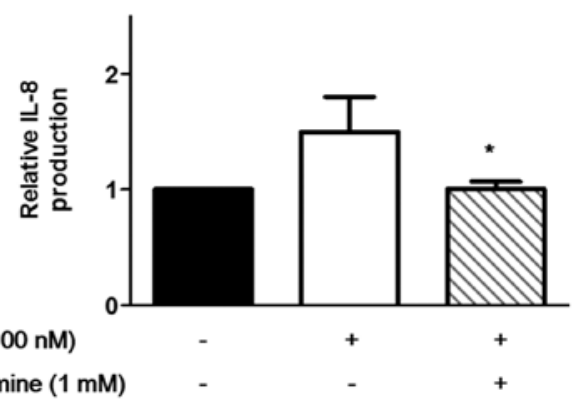

Figure 5. Inhibitory effects of ketamine on the production of interleukin (IL)-6 and IL-8 induced by substance P (SP). The U373MG cells were plated into 12 -well tissue culture plates at a density of $2 \times 10^{5}$ cells/well and incubated in MEM supplemented with 10\% FBS for $12 \mathrm{~h}$, followed by incubation in MEM supplemented with $0.5 \% \mathrm{FBS}$ for $12 \mathrm{~h}$ at $37^{\circ} \mathrm{C}$. Subsequently, the cells were incubated with or without ketamine $(1 \mathrm{mM})$ for $60 \mathrm{~min}$, and then incubated with or without SP $(100 \mathrm{nM})$. After $24 \mathrm{~h}$, the culture supernatants were harvested, and the levels of (A) IL-6 and (B) IL-8 were measured using a cytometric bead array. Data are the means \pm SD of 3 separate experiments, and expressed relative to the cells incubated without SP and ketamine. Data are compared between the SP-stimulated cells incubated with and without ketamine. ${ }^{*} \mathrm{P}<0.05$.

this cell line is widely used as an in vitro model in order to analyze the functions of the NK-1R. Previously, it has been demonstrated that the plasma levels of ketamine reached up to $25,800 \mathrm{ng} / \mathrm{ml}(108.4 \mu \mathrm{M})$ in surgical patients $1 \mathrm{~min}$ after an intravenous injection of ketamine at a dose of $2.0-2.2 \mathrm{mg} /$ $\mathrm{kg}$ (28). In the present study, we revealed that the phosphorylation of ERK $1 / 2$ was only minimally inhibited by $0.1 \mathrm{mM}$ ketamine, whereas the dose of $1 \mathrm{mM}$ ketamine caused a marked inhibition. Thus, it is possible that clinically relevant $(100 \mathrm{mM})$ or higher concentrations of ketamine modulate the inflammatory responses of SP-stimulated NK-1R-expressing cells in vivo by suppressing the activation of signaling molecules (such as ERK1/2, p38 MAPK and NF-kB).

Neuroinflammation is involved in several diseases affecting the central nervous system (CNS) in humans, such as Parkinson's disease (PD) $(29,30)$. As regards the pathogenesis of PD, neuroinflammation is a common feature, which is primarily induced by the long-term activation of glial cells (astrocytes and microglia) in the brain (31). It has also been demonstrated that activated glial cells produce pro-inflammatory cytokines, which play roles in the initiation and progression of neuroinflammation (29). Thus, anti-inflammatory drugs may be expected to reduce the risk and delay the pathogenic process of neuroinflammation by suppressing the activation of glial cells (32). Ketamine has been identified as a non-selective NMDA receptor antagonist. The pharmacological actions of ketamine include the 
regulation of inflammatory and immune responses in neural tissues, which leads to decreases in the levels of proinflammatory cytokines including IL-6 and IL-8. Previously, ketamine has been reported to exert an anti-inflammatory effect on LPS-stimulated macrophages in vitro and in vivo by suppressing the MAPK pathways $(33,34)$. The glial cells of the CNS are involved in regulating the immune response under conditions of neuropathic pain (35) and ketamine has been shown to reduce the LPS-induced production of TNF- $\alpha$ and prostaglandin E2 by astrocytes (36). Moreover, ketamine exerts an inhibitory effect on the activation of LPS-stimulated astrocytes by suppressing $\mathrm{NF}-\kappa \mathrm{B}$ activation through the reduction of Toll-like receptor 4 expression (26). As regards the effect of ketamine on the NK-1R, Okamoto et al demonstrated that ketamine inhibited NK-1R-mediated signaling by interfering with the binding of SP using NK-1R-expressing Xenopus oocytes using a whole-cell voltage clamp; however, the binding site of ketamine in the NK-1R is probably different from that of SP (24). Thus, the precise mechanism through which ketamine modulates SP-induced signaling remains unknown.

SP stimulates a number of intracellular signaling molecules, including members of the MAPK family (ERK1/2 and p38 MAPK) via the action of NK-1R. In fact, SP has been demonstrated to enhance the production of inflammatory chemokines by murine macrophages through ERK/p38 MAPK-mediated NF- $\kappa$ B activation (37). Moreover, it has been previously demonstrated that SP induces the expression of IL- 6 through the activation of p38 MAPK, ERK1/2 and $\mathrm{NF}-\kappa \mathrm{B}$ in the U373MG astrocytoma cell line, which was also used in the present study $(14,38)$. Taken together, these observations suggest that SP induces the production of cytokines/chemokines by NK-1R-expressing cells through the NK-1R, a principal receptor for SP, followed by the activation of signaling molecules (ERK1/2, p38 MAPK and NF- $\mathrm{BB}$ ). Of note, ketamine may inhibit NK-1R-mediated signaling by interfering with the binding of SP to the receptor (24). Thus, ketamine may suppress the SP-induced activation of signaling molecules (ERK1/2, p38 MAPK and NF- $\mathrm{B}$ ), thereby suppressing the production of cytokines/chemokines by exerting an inhibitory effect on the NK-1R (interference of SP binding with the receptor).

In conclusion, our results demonstrate that ketamine inhibits the SP-induced phosphorylation of MAPK (ERK1/2 and p38 MAPK) and NF- $\mathrm{KB}$, and suppresses the production of the proinflammatory cytokines IL- 6 and IL-8. Moreover, the anti-inflammatory effect of ketamine is potentially mediated through the inhibition of signaling molecules (MAPK and $\mathrm{NF}-\kappa \mathrm{B}$ ). Thus, ketamine may modulate SP-induced inflammatory responses by NK-1R-expressing cells through the suppression of signaling molecules (such as ERK1/2, p38 MAPK and NF- $\kappa$ B); however, a detailed examination of the anti-inflammatory effects of ketamine on glial cells (such as astrocytes and microglia cells) is warranted in the future.

\section{Acknowledgements}

The present study was supported by a Grant-in-Aid for Scientific Research (grant no. 23592265) from the Japan Society for the Promotion of Science.

\section{References}

1. Guha S, Eibl G, Kisfalvi K, Fan RS, Burdick M, Reber H, Hines OJ, Strieter R and Rozengurt E: Broad-spectrum G protein-coupled receptor antagonist, [D-Arg1,D-Trp5,7,9,Leu11] SP: a dual inhibitor of growth and angiogenesis in pancreatic cancer. Cancer Res 65: 2738-2745, 2005.

2. Esteban F, Muñoz M, González-Moles MA and Rosso M: A role for substance $\mathrm{P}$ in cancer promotion and progression: a mechanism to counteract intracellular death signals following oncogene activation or DNA damage. Cancer Metastasis Rev 25: 137-145, 2006.

3. Muñoz M, Rosso M and Coveñas R: A new frontier in the treatment of cancer: NK-1 receptor antagonists. Curr Med Chem 17: 504-516, 2010.

4. Samsam M, Coveñas R, Ahangari R, Yajeya J, Narváez JA and Tramu G: Simultaneous depletion of neurokinin A, substance P and calcitonin gene-related peptide from the caudal trigeminal nucleus of the rat during electrical stimulation of the trigeminal ganglion. Pain 84: 389-395, 2000.

5. Bang R, Sass G, Kiemer AK, Vollmar AM, Neuhuber WL and Tiegs G: Neurokinin-1 receptor antagonists CP-96,345 and L-733,060 protect mice from cytokine-mediated liver injury. J Pharmacol Exp Ther 305: 31-39, 2003.

6. Muñoz M and Rosso M: The NK-1 receptor antagonist aprepitant as a broad spectrum antitumor drug. Invest New Drugs 28: 187-193, 2010.

7. Samsam M, Coveñas R, Csillik B, Ahangari R, Yajeya J, Riquelme R Narváez JA and Tramu G: Depletion of substance P, neurokinin $\mathrm{A}$ and calcitonin gene-related peptide from the contralateral and ipsilateral caudal trigeminal nucleusfollowing unilateral electrical stimulation of the trigeminal ganglion; apossible neurophysiological and neuroanatomical link to generalized head pain. J Chem Neuroanat 21: 161-169, 2001.

8. Muñoz M and Coveñas R: Involvement of substance $P$ and the NK-1 receptor in cancer progression. Peptides 48: 1-9, 2013.

9. Maeno H, Kiyama $\mathrm{H}$ and Tohyama M: Distribution of the substance $\mathrm{P}$ receptor (NK-1 receptor) in the central nervous system. Brain Res Mol Brain Res 18: 43-58, 1993.

10. Saffroy M, Beaujouan JC, Torrens Y, Besseyre J, Bergström L and Glowinski J: Localization of tachykinin binding sites (NK1, NK2, NK3 ligands) in the rat brain. Peptides 9: 227-241, 1988.

11. Wolf SS, Moody TW, Quirion R and O'Donohue TL: Biochemical characterization and autoradiographic localization of central substance P receptors using [125I]physalaemin. Brain Res 332: 299-307, 1985.

12. Lieb K, Schaller H, Bauer J, Berger M, Schulze-Osthoff K and Fiebich BL: Substance P and histamine induce interleukin-6 expression in human astrocytoma cells by a mechanism involving protein kinase $\mathrm{C}$ and nuclear factor-IL-6. J Neurochem 70: 1577-1583, 1998.

13. Lieb K, Fiebich BL, Berger M, Bauer J and Schulze-Osthoff K: The neuropeptide substance $\mathrm{P}$ activates transcription factor NF-kappa B and kappa B-dependent gene expression in human astrocytoma cells. J Immunol 159: 4952-4958, 1997.

14. Horuk R, Martin AW, Wang Z, Schweitzer L, Gerassimides A, Guo H, Lu Z, Hesselgesser J, Perez HD, Kim J, et al: Expression of chemokine receptors by subsets of neurons in the central nervous system. J Immunol 158: 2882-2890, 1997.

15. Kim SY, Bae JC, Kim JY, Lee HL, Lee KM, Kim DS and Cho HJ: Activation of p38 MAP kinase in the rat dorsal root ganglia and spinal cord following peripheral inflammation and nerve injury. Neuroreport 13: 2483-2486, 2002.

16. Ji RR, Befort K, Brenner GJ and Woolf CJ: ERK MAP kinase activation in superficial spinal cord neurons induces prodynorphin and NK-1 upregulation and contributes to persistent inflammatory pain hypersensitivity. J Neurosci 22: 478-485, 2002.

17. Jin SX, Zhuang ZY, Woolf CJ and Ji RR: p38 mitogen-activated protein kinase is activated after a spinal nerve ligation in spinal cord microglia and dorsal root ganglion neurons and contributes to the generation of neuropathic pain. J Neurosci 23: 4017-4022, 2003.

18. Huang WJ, Wang BR, Yao LB, Huang CS, Wang X, Zhang P, Jiao XY, Duan XL, Chen BF and Ju G: Activity of p44/42 MAP kinase in the caudal subnucleus of trigeminal spinal nucleus is increased following perioral noxious stimulation in the mouse. Brain Res 861: 181-185, 2000.

19. Ji RR, Baba H, Brenner GJ and Woolf CJ: Nociceptive-specific activation of ERK in spinal neurons contributes to pain hypersensitivity. Nat Neurosci 2: 1114-1119, 1999. 
20. Lazarewicz JW, Wroblewski JT and Costa E: N-methyl-D-aspartate-sensitive glutamate receptors induce calcium-mediated arachidonic acid release in primary cultures of cerebellar granule cells. J Neurochem 55: 1875-1881, 1990.

21. Kim DK, Rordorf G, Nemenoff RA, Koroshetz WJ and Bonventre JV: Glutamate stably enhances the activity of two cytosolic forms of phospholipase A2 in brain cortical cultures. Biochem J 310: 83-90, 1995.

22. Chen QR, Miyaura C, Higashi S, Murakami M, Kudo I, Saito S, Hiraide T, Shibasaki Y and Suda T: Activation of cytosolic phospholipase A2 by platelet-derived growth factor is essential for cyclooxygenase-2-dependent prostaglandin E2 synthesis in mouse osteoblasts cultured with interleukin-1. J Biol Chem 272: $5952-5958,1997$.

23. Zeilhofer HU, Swandulla D, Geisslinger G and Brune K: Differential effects of ketamine enantiomers on NMDA receptor currents in cultured neurons. Eur J Pharmacol 213: 155-158, 1992.

24. Okamoto T, Minami K, Uezono Y, Ogata J, Shiraishi M, Shigematsu A and Ueta Y: The inhibitory effects of ketamine and pentobarbital on substance $\mathrm{p}$ receptors expressed in Xenopus oocytes. Anesth Analg 97: 104-110, 2003.

25. Mazar J,Rogachev B, Shaked G,Ziv NY, CzeigerD, Chaimovitz C, Zlotnik M, Mukmenev I, Byk G and Douvdevani A: Involvement of adenosine in the antiinflammatory action of ketamine. Anesthesiology 102: 1174-1181, 2005.

26. Wu Y,Li W, Zhou C, Lu F, Gao T, Liu Y, Cao J, Zhang Y, Zhang Y and Zhou C: Ketamine inhibits lipopolysaccharide-induced astrocytes activation by suppressing TLR4/NF-kB pathway. Cell Physiol Biochem 30: 609-617, 2012.

27. Heuillet E, Ménager J, Fardin V, Flamand O, Bock M, Garret C, Crespo A, Fallourd AM and Doble A: Characterization of a human NK1 tachykinin receptor in the astrocytoma cell line U 373 MG. J Neurochem 60: 868-876, 1993.

28. Domino EF, Zsigmond EK, Domino LE, Domino KE, Kothary SP and Domino SE: Plasma levels of ketamine and two of its metabolites in surgical patients using a gas chromatographic mass fragmentographic assay. Anesth Analg 61: 87-92, 1982.

29. Niranjan R: The role of inflammatory and oxidative stress mechanisms in the pathogenesis of Parkinson's disease: focus on astrocytes. Mol Neurobiol 49: 28-38, 2014.

30. Simões AP, Duarte JA, Agasse F, Canas PM, Tomé AR, Agostinho P and Cunha RA: Blockade of adenosine A2A receptors prevents interleukin-1 $\beta$-induced exacerbation of neuronal toxicity through a $\mathrm{p} 38$ mitogen-activated protein kinase pathway. J Neuroinflammation 9: 204, 2012.
31. Minagar A, Shapshak P, Fujimura R, Ownby R, Heyes M and Eisdorfer C: The role of macrophage/microglia and astrocytes in the pathogenesis of three neurologic disorders: HIV-associated dementia, Alzheimer disease, and multiple sclerosis. J Neurol Sci 202: 13-23, 2002.

32. García-Bueno B, Madrigal JL, Lizasoain I, Moro MA, Lorenzo P and Leza JC: Peroxisome proliferator-activated receptor gamma activation decreases neuroinflammation in brain after stress in rats. Biol Psychiatry 57: 885-894, 2005.

33. Wu GJ, Chen TL, Ueng YF and Chen RM: Ketamine inhibits tumor necrosis factor-alpha and interleukin- 6 gene expressions in lipopolysaccharide-stimulated macrophages through suppression of Toll-like receptor 4-mediated c-Jun N-terminal kinase phosphorylation and activator protein-1 activation. Toxicol Appl Pharmacol 228: 105-113, 2008.

34. Chang HC, Lin KH, Tai YT, Chen JT and Chen RM: Lipoteichoic acid-induced TNF- $\alpha$ and IL- 6 gene expressions and oxidative stress production in macrophages are suppressed by ketamine through downregulating Toll-like receptor 2-mediated activation oF ERK1/2 and NFKB. Shock 33: 485-492, 2010.

35. Milligan ED and Watkins LR: Pathological and protective roles of glia in chronic pain. Nat Rev Neurosci 10: 23-36, 2009.

36. Shibakawa YS, Sasaki Y, Goshima Y, Echigo N, Kamiya Y, Kurahashi K, Yamada Y and Andoh T: Effects of ketamine and propofol on inflammatory responses of primary glial cell cultures stimulated with lipopolysaccharide. Br J Anaesth 95: 803-810, 2005

37. Sun J, Ramnath RD, Zhi L, Tamizhselvi R and Bhatia M: Substance $P$ enhances NF-kappaB transactivation and chemokine response in murine macrophages via ERK1/2 and p38 MAPK signaling pathways. Am J Physiol Cell Physiol 294: C1586-C1596, 2008.

38. Fiebich BL, Schleicher S, Butcher RD, Craig A and Lieb K: The neuropeptide substance $\mathrm{P}$ activates $\mathrm{p} 38$ mitogen-activated protein kinase resulting in IL-6 expression independently from NF-kappaB. J Immunol 165: 5606-5611, 2000. 